\section{BRIDGING THE GULF}

Sir, the authors of Developing the continuum of dental education: including dental foundation trainers in the delivery of a community-based clinical teaching programme (BDJ 2012; 213: 517-521) have emphasised the importance of preparing final year dental students for the dental foundation training programme. They have also outlined the thoughtprovoking benefits of including local dental foundation trainers (educational supervisors) in a community-based undergraduate programme. Whilst it is admirable to consider the participation of local dental foundation trainers (educational supervisors) at undergraduate level, one must bear in mind that it will not always be as straightforward for some postgraduate deanery dental foundation trainers to work with dental schools in a similar manner. This is because, unlike Wales, there are some postgraduate dental deaneries that do not have a dental school located within their footprint.

Perhaps a way of 'developing the continuum of dental education' could be for dental school students to use the same electronic personal development plan (e-PDP) at dental school as at dental foundation training level. That way any learning needs will be conveniently identified for dental foundation trainers as opposed to them seemingly working in the dark at the beginning of the dental foundation training year to identify these needs.

The authors suggest a source of tension existing at the divergence of undergraduate teaching and 'accepted practice' amongst established general dental practitioners. Others have referred to the transition between undergraduate teaching and general dental practice as a gap or even a gulf. Taking undergraduates from the relatively sheltered confines of their dental school and 'dipping' them into the community-based outreach environment is highly beneficial but not new, neither is their exposure to GDP supervisors. In my mind bridging the gap (pun intended), as opposed to announcing a 'mind the gap' warning message, can also be achieved through enabling undergraduates to practise 'accepted practice' skills, such as carving amalgam restorations, using pins and a ParaPost kit, at the earlier phantom head/ extracted teeth stage of teaching.

The authors also raise an interesting point about whether dental schools should limit their teaching to treatments provided within NHS-funded dentistry. In order to accurately authenticate the general dental practice experience for undergraduates, it is important to consider introducing nonNHS clinical treatments to the armoury of dental school students. Indeed, this is something which the Leicester Dental Teaching Academy in partnership with the University of Buckingham may have already identified.

A. Rai, by email

DOI: 10.1038/sj.bdj.2013.171

\section{THE NEED TO REVEAL}

Sir, I read with interest the conclusion of the two-year study (BDJ 2012; 213: 594) that the incidence of bisphosphonaterelated osteonecrosis (BRONJ) is rare.

During the period covered by the study I saw, in my single-handed general practice, two patients who fulfilled the criteria for a diagnosis of BRONJ.

The first patient was a 63-year-old female with a history of breast cancer and bony metastases. She was receiving intravenous bisphosphonate therapy, Zoledronic acid, $4 \mathrm{mg}$ monthly, together with a cocktail of other medication. Following extraction of a mandibular molar under intravenous antibiotics she developed a bony sequestrum but following a further procedure to remove necrotic bone made a good recovery.

The second patient was a 68-year-old female with a long history of rheumatoid arthritis. Following extraction of a mandibular molar the extraction site failed to heal. Although she had revealed she was taking prednisolone and methotrexate she omitted to reveal she was also on Alendronic acid $5 \mathrm{mg}$ weekly. It was only following referral to hospital that further investigation revealed oral bisphosphonate therapy. Following removal of necrotic bone and curettage the patient made a good recovery and further extractions have been carried out with intravenous antibiotic cover that have proved uneventful. The Alendronic acid has now been discontinued.

These two cases highlight the need in general practice to identify those patients at risk from BRONJ. One, correctly identified, received appropriate hospital treatment. The other, however, failed to reveal the extent of her medication, perhaps not understanding the relevance. With the widespread prescription of bisphosphonates patients need to be fully informed by their medical practitioners of the possible risk of BRONJ. In addition, we as dentists must ensure that patients understand the need to reveal all their medication when asked.

\section{G. Feaver} London DOI: 10.1038/sj.bdj.2013.172

\section{A SET GLOBAL POLICY}

Sir, in response to the letter My nonjob (BDJ 2013; 214: 6), unfortunately I think we have entered the world of risk assessment in which reams of pointless paperwork are only for someone else to justify their existence. When the CQC was first rolled out, I distinctly remember that the representative who came to talk about $\mathrm{CQC}$ requirements was clearly out of her depth and was instantly swamped by the congregation. This goes to show that Dr Mackay is quite right when he says he feels suffocated by all this bureaucracy and cannot do what he is actually trained to do when an official who has probably had only weeks of training demands this and that. Surely it is the CQC who should be writing/formatting the policies and updating them, and doing the non-job stuff, for the dentist to comply with it. The CQC should have a set global policy for everyone. The CQC has a role, but I am not sure they do within dentistry; we have our own regulatory body called the GDC.

\section{Parsons}

Sheffield

DOI: 10.1038/sj.bdj.2013.173

The $B D J$ website now includes a facility enabling readers to immediately comment on letters. All comments must comply with the nature.com Terms and Conditions and Community Guidelines visit the $B D J$ website to find out more and to post your comment now. 